\title{
Engaging the Community in Project SKIP to Promote Early Years Physical Literacy in Indonesia
}

\author{
Jacqueline D. Goodway \\ Department of Human Sciences \\ The Ohio State University \\ Columbus, USA \\ goodway.1@osu.edu
}

\author{
Ruri Famelia \\ Department of Human Sciences \\ The Ohio State University \\ Columbus, USA \\ famelia.1@osu.edu \\ Faculty of Sports Science \\ State University of Padang \\ Padang, Indonesia
}

\author{
Yung-Ju Chen \\ Department of Human Sciences \\ The Ohio State University \\ Columbus, USA \\ chen.5766@osu.edu
}

\begin{abstract}
-global increases in childhood overweight and obesity and decreases in physical activity warrant evidencedbased approaches to addressing this health concern. These concerns are compounded by the fact that many young children start life with significant delays in critical fundamental motor skills (FMS) needed to support an active lifestyle. Thus, communities need to begin to meet the physical literacy needs of their children and implement culturally relevant physical activity programs. One such approach is an early years motor skill program called $S K I P^{\odot}$ that is based on 28 years of data. $S K I P^{\odot}$ aims to promote FMS competence of young children. A variety of $S K I P^{\odot}$ studies using different pedagogical approaches, and both expert and trained-teacher implementers have revealed positive outcomes for the children involved. These findings have implications for early childhood care settings and community-based sport policy.
\end{abstract}

Keywords-fundamental motor skills, object control skills, locomotor skills, motor skill intervention, preschoolers.

\section{INTRODUCTION}

This paper will provide a developmental perspective on the need to implement movement and physical activity programs for young children within the community. It will provide a brief overview of physical literacy and summarize a developmental, theoretical model as the theoretical lens for the implementation of community-based early childhood movement programs. A brief rationale for the need for early childhood programs will be provided and the Successful Kinesthetic Instruction for Preschoolers $\left(S K I P^{\odot}\right)$ program developed by Goodway and colleagues will be offered as a community solution to promote motor competence and physical activity in young children. The content and evolution of $S K I P^{\odot}$ will be discussed, along with a summary of the $S K I P^{\odot}$ intervention literature. The paper will conclude with recommendations for policy and professional practice.

\section{Chilhood OverweIGHT AND OBESITY AND PHYSICAL ACTIVITY}

Across the world, rates of childhood obesity are high and continuing to rise [1]. Correspondingly, children have low levels of moderate to vigorous physical activity (MVPA) and increasing amounts of sedentary behavior [2], often spending much of their day on screens $[3,4,5]$. These trends are also reported for Indonesian children, and are compounded by the wide-scale migration from rural to urban environments $[6,7,8,9,10,11]$. Overall, the accumulation of such data place children at great risk for hypokinetic diseases and place a high priority on population-based approaches to tackling these issues. The World Health Organization (WHO) has suggested that government agencies, the education sector, and the private sector have a key role to play in shaping healthy communities [12]. Furthermore, community-based interventions should be multi-component and adapted to the local context [12]. Moreover, scholars within Indonesia and the WHO suggest that early action is required to promote and support the physical activity behaviors of children and we should look to our early childhood care settings to implement community-based physical activity interventions $[12,13]$. From a developmental perspective, it is clear that we need to look to our early childhood years where children begin to learn physical activity behaviors, develop motor competence, and build their perceptions and motivations to be motor competent and active. We need to provide our young children with an active start and start them on the road to their physical literacy journey.

\section{IMPORTANCE AND DEFINITIONS OF PHYSICAL LITERACY}

Physical literacy is a concept that is gaining world-wide attention. Across the globe, many countries are beginning to develop physical literacy policies and programs that have implications for professional practice in sport and physical education, as well as the health of the nation. One of the early definitions of physical literacy by Whitehead described it as the "motivation, confidence, physical competence, knowledge and understanding to value and take responsibility for engagement in physical activities for life [14]. Since that time, various countries such as Canada and Australia have developed different physical literacy definitions [15,16,17]. However, all include the core constructs of: 1) movement/physical competence, 2) motivation and confidence to move, 3) knowledge and understanding of the how, why and when of movement, 4) inclusive physical activities nurtured across the lifespan, and 5) that each person's physical literacy journey is unique to them.

A recent paper by Dudley, Cairney, Wainwright, Kriellaars \& Mitchell (2017) suggested that if we are to 
develop effective physical literacy policies within sport, physical education and public health there are four key ingredients [18]. The first is the development of movement competence, especially in the early childhood and primary school years. The second is having access to movement (and movement programs) in a variety of different contexts. The third key ingredient is the notion of individual physical literacy journeys that change across the lifespan. The fourth reflects the power structures of movement, that is, ensuring there is equal access to physical activities across gender, disability, race/ethnicity, religion, and poverty. Overall, Dudley et al. [18] suggest we need to look carefully at our communities and examine the ways in which we can develop effective physical literacy policies and programs for our children (and adults). Of these four pillars of physical literacy, we believe that the development of motor competence in the early years is particularly important.

\section{DEVElopmental TRAJECTORY MODEl of MOTOR DEVELOPMENT}

A well-cited model of motor development by Stodden and colleagues $[19,20]$ supports the ideas proposed by physical literacy. At the heart of this model is a bi-directional and synergistic, relationship between motor competence and physical activity. Opportunities to be physically active (or not be active) in the community influences a young child's (preschool) ability to develop motor competence. Motor competence will be delayed and low for those children growing up in poor, urban communities with limited contexts and programs to promote physical activity and develop motor competence [21]. However, over time, by the middle of primary school, a child's motor competence increasingly determines whether she/he will choose to engage in physical activity when given the opportunities to do so. The take home message from this part of the model is that young children should be provided with developmentally appropriate opportunities to be active in the early years in their communities to drive the development of motor competence.

Another integral part of the model is the notion of perceptions of motor competence. Perceived motor competence (how a child feels about their actual motor competence) influences a child's physical activity levels and corresponding motor competence [19]. In the early childhood years children have limited cognitive abilities to assess their actual motor competence, and we see very inflated levels of perceived motor competence that are often not in line with reality $[22,23,24]$. Although the lack of alignment between actual and perceived motor competence can be an issue later in childhood, for the preschool and early primary school-aged child, these high perceptions of motor competence can be considered a valuable asset in the implementation of community physical activity programs. The literature suggests that many preschool and kindergarten children feel "pretty good" about their physical activities $[24,25,26]$ and as a result are motivated and excited to participate in motor skill programs such as $S K I P^{\odot}$. By around 7-8 years of age, increasing cognitive skills (shifting from preoperations to concrete operations stage of cognitive development) results in children more accurately aligning their perceptions of motor competence with their actual motor competence. For those children with low motor competence, high levels of perceived motor competence will drop dramatically and children often begin to drop out of sport and physical activities when given the option to do so [21]. For many of these low motor competent children, they are drawn into a negative spiral of disengagement in physical activity and sport [19,21]. There is an emerging body of literature supporting this model and Robinson et al. [21] provide a nice overview of the scientific evidence. The overall message from the developmental trajectory model [19] is that we need to make sure that children develop motor competence in the early childhood years through evidenced-based motor skill programming such as $S K I P^{\odot}$

\section{DEVELOPMENTAL DELAYS AND GENDER DIFFERENCES}

Many children who grow up in poverty do not have the opportunities to develop fundamental motor skill (FMS) competence $[27,28,29,30,31]$ and are developmentally delayed $\left(<25^{\text {th }}\right.$ percentile in FMS $)$ in their FMS. Locomotor skills move the body through space [39] and include run, gallop, hop, skip, jump, leap, slide \& creative locomotor skills. Object control skills involve manipulating an object [39] and incorporate catch, throw, kick, punt, hand dribble, foot dribble, strike, and roll. FMS consist of locomotor skills like running and jumping and skipping and object control skills such as catching, throwing and kicking. A fairly large study of preschool children enrolled in Head Start in the USA $(N=275)$ found that preschoolers were between the $10^{\text {th }}$ to $17^{\text {th }}$ percentile for locomotor skills and around the $16^{\text {th }}$ percentile for manipulative skills [29]. Furthermore, $84-91 \%$ of the preschoolers in the sample demonstrated a delay. The findings from this study and others within the USA suggest that regardless of ethnicity and geographic location, young children growing up in disadvantaged settings demonstrate delays in FMS that represent a significant concern [29,32,33]. Developmental delays in FMS have also been found outside of the USA with both Indonesian [26,34] and Brazilian [32] children living in urban centers demonstrating significant developmental delay.

In all of these studies, there were significant gender trends. The motor development literature has consistently found that there are no gender differences in locomotor skills but there are gender differences in object control skills $[27,28,29,31,35]$. It is not clear from the research literature why such gender differences exist, but for the past decade, these findings have remained consistent. Overall, the data on developmental delay and gender differences provide evidence that early motor skill and physical activity interventions are warranted.

\section{SUCCESSFUL KINESTHETIC INSTRUCTION FOR PRESCHOOLERS (SKIPC) MOTOR SKILL PROGRAM}

The $S K I P^{\odot}$ program is an evidenced-based motor skill program developed by Goodway and colleagues, largely at The Ohio State University, for young children (aged 3-8 years) over the past 28 years. $S K I P^{\odot}$ is designed to promote early years physical literacy and is theoretically underpinned by dynamic systems theory \& Newell's constraints 
perspective [36,37]. SKIP ${ }^{\odot}$ is continually evolving based on the research evidence with a primary focus on intervening with young children who are developmentally delayed in motor competence, especially those from low socioeconomically deprived environments \& urban areas.

In order to describe $S K I P^{\odot}$ we will draw from Metzler's [38] pedagogical model approach, specifically referring to: 1) theoretical foundation, 2) intended learning outcomes of $\left.S K I P^{\odot}, 3\right)$ developmentally appropriate learning activities and unique task structures, and 4) child learning outcomes.

\section{A. Theoretical Underpinning of SKIP (C)}

Newell's constraints theory [36,37] suggests that movement is a product of the interaction between and among constraints from the: 1) individual, 2) environment, and 3) task. For example in the task of catching, individual constraints might be factors such as the child's ability to track the ball, their hand-eye coordination, fine motor development and reaction time to the ball tossed. Children who are low in these abilities will have little success in catching a ball with their hands. However, environmental constraints will also influence a child's success in catching a ball. Factors such as ball size, shape, density and texture along with ball color will influence the ability to catch a ball. Additionally, task constraints such as distance from the tosser, speed of the toss, trajectory of the toss, and location of where the ball is tossed to (e.g. directly to body or away from it) will influence catching success. Together the interaction of constraints imposed from the child, environment (equipment) and task will determine a child's motor performance in a skill.

\section{B. Developmentally Appropriate Learning Activities and Unique Task Structures}

A core concept of $S K I P^{\odot}$ is that it is not a static curriculum, rather it is dynamic and changing based upon the local context and the children involved in the program. At the heart of $S K I P$ ' $S^{\odot}$ core principles is that all instruction starts from the child. We need to consider the individual constraints (e.g. hand-eye coordination) that influence the child and his/her performance \& accommodate them in the development of tasks that align with a child's level. That is, we need to modify the environment to provide a "Goodness of Fit" with child development and select equipment that matches the developmental level of the child \& accommodates for individual constraints. We then select developmentally appropriate tasks based on a child's developmental stage, underlying constraints, and the types of environmental manipulation. In the catching example above, a child with poor hand-eye coordination and an inability to track the ball should be given a large, soft foam ball, tossed from a close distance, directly to the chest. In contrast, a child in the same program with better hand-eye coordination may catch a beanbag tossed from a larger distance to the side of the child. As children improve their skills we should be continually manipulating task and environmental constraints to meet the developmental needs of the child at that specific point in time and have an array of tasks within the same lesson to individualize tasks to each child. Thus $S K I P^{\odot}$ is a curricular approach that is continually evolving and aligned to a child's developmental level.

\section{SKIP C Key Learning Outcomes and Content Areas}

The key learning outcomes for $S K I P^{\odot}$ consist of outcomes in four learning areas: 1) physical and motor competence, 2) knowledge and understanding, 3) motivation, confidence and enjoyment, and, 4) wrap around engagement in physical activities for life. These outcomes are listed below.

Physical and Motor Competence:

- Promote movement competence: FMS competence, movement concepts, body awareness, culturally relevant forms of movement

- Learn to move in different environments, with different equipment $\&$ individuals

- Engage in and increase total physical activity \& MVPA

- Participate in developmentally appropriate health-related fitness activities

Knowledge \& Understanding:

- Of the body \& it's response to physical activity

- Of the importance of physical activity to a healthy body $\&$ lifestyle

- Of movement principles

- Learning how to learn how to move

Motivation, Confidence \& Enjoyment:

- Improve individual perceptions of motor competence \& motivation to be active - choose to be active

- Promote personal-social responsible behaviors in activity environments

- Task persistence in a variety of challenging movement contexts

Wrap-Around Engagement in Physical Activities for Life:

- Promote at home parent-child physical activity

- "Camouflage" (build in) motor skill/physical activities to the everyday classroom routine

- Develop an appreciation of an active lifestyle across the lifespan

- Enjoy moving, be a mover, believe "I am a mover"

The actual content of $S K I P^{\odot}$ includes FMS, including locomotor and object control skills [39]. Other content areas include movement concepts and health-related fitness. Other potential activities in $S K I P^{\odot}$ include dance and gymnastics. There is really no limit to the content of $S K I P^{\odot}$ as the most important principle is that the activities are developmentallyaligned with the child and reflect the types of activities that are conducted in the local community and culture.

$S K I P^{\odot}$ develops many of the skills identified above which are often represented on the mountain of motor development [40]. However, it is important to note that in the engaging in FMS there is much more going on developmentally. Below the surface of the skill, important capacities are being developed that often cannot be observed directly. However, these capacities can be applied across multiple movement contexts across the lifespan. Such capacities include factors like: multi-limb coordination, manual dexterity, dynamic strength, speed of limb movement and balance. For example, object control skills such as kicking, throwing and striking work on a child's dynamic balance, as do locomotor skills like running, jumping and skipping. As a child participates in $S K I P^{\odot}$ he or she will begin to learn how to manage her/his center of mass over the base of support and gradually improve his/her balance. 
These balance skills can then be applied in many different movement contexts such as dance, riding a bike, playing on the playground, and hiking on the side of a mountain. Thus, when children participate in $S K I P^{\odot}$, they are developing a set of capacities that can be functionally used across the lifespan to support their physical literacy journey.

TABLE I. EFECT SIZES COMPARISON OF SKIPC STUDIES

\begin{tabular}{|c|c|c|c|c|c|}
\hline Study & Country & Duration & Dose & $\begin{array}{c}\text { Delivered } \\
\text { by }\end{array}$ & Cohens'd \\
\hline $\begin{array}{c}\text { SKIPC } \\
{[27]}\end{array}$ & USA & $\begin{array}{c}12 \text { weeks, } \\
2 \times 45 \\
\text { mins. }\end{array}$ & $\begin{array}{c}1080 \\
\text { mins. }\end{array}$ & $\begin{array}{c}\text { Motor } \\
\text { development } \\
\text { experts }\end{array}$ & 3.06 \\
\hline $\begin{array}{c}\text { SKIPC } \\
{[31]}\end{array}$ & USA & $\begin{array}{c}8 \text { weeks, } \\
2 \times 30 \\
\text { mins }\end{array}$ & $\begin{array}{c}480 \\
\text { mins. }\end{array}$ & $\begin{array}{c}\text { Motor } \\
\text { development } \\
\text { experts }\end{array}$ & 3.96 \\
\hline $\begin{array}{c}\text { SKIPC } \\
{[44]}\end{array}$ & USA & $\begin{array}{c}8 \text { weeks, } \\
2 \times 30 \\
\text { mins. }\end{array}$ & $\begin{array}{c}480 \\
\text { mins. }\end{array}$ & $\begin{array}{c}\text { Preschool } \\
\text { teachers }\end{array}$ & 2.27 \\
\hline $\begin{array}{c}\text { SKIPC } \\
{[45]}\end{array}$ & USA & $\begin{array}{c}6 \text { weeks, } \\
2 \times 30 \\
\text { mins }\end{array}$ & $\begin{array}{c}360 \\
\text { mins. }\end{array}$ & $\begin{array}{c}\text { Preschool } \\
\text { teachers }\end{array}$ & 2.50 \\
\hline $\begin{array}{c}I N D O- \\
\text { SKIPC } \\
{[26]}\end{array}$ & Indonesia & $\begin{array}{c}8 \text { weeks, } \\
2 \times 30 \\
\text { mins. }\end{array}$ & $\begin{array}{c}480 \\
\text { mins. }\end{array}$ & $\begin{array}{c}\text { Preschool } \\
\text { teachers }\end{array}$ & 2.21 \\
\hline $\begin{array}{c}\text { SKIP- } \\
\text { CYMR }\end{array}$ & Wales & $\begin{array}{c}8 \text { weeks, } \\
2 \times 30 \\
\text { mins. }\end{array}$ & $\begin{array}{c}480 \\
\text { mins. }\end{array}$ & $\begin{array}{c}\text { Preschool } \\
\text { teachers }\end{array}$ & 0.91 \\
\hline $\begin{array}{c}\text { RaMPP } \\
{[42]}\end{array}$ & USA & $\begin{array}{c}6 \text { weeks, } \\
2-3 \times 30 \\
\text { mins. }\end{array}$ & $\begin{array}{c}360- \\
540 \\
\text { mins. }\end{array}$ & $\begin{array}{c}\text { Motor } \\
\text { development } \\
\text { experts + } \\
\text { Preschool } \\
\text { teachers }\end{array}$ & 1.12 \\
\hline & & $\begin{array}{c} \\
\end{array}$ & & & \\
\hline
\end{tabular}

\section{EVOLUTION OF SKIP C}

$S K I P^{\odot}$ has evolved over the past 27 years to include a variety of approaches to promoting physical literacy in young children. It is not possible within this paper to provide an extensive review of the $S K I P^{\odot}$ literature, rather we will try to provide a brief overview of the $S K I P^{\odot}$ studies and conclude with evidenced-based implications for early motor skill intervention.

A number of $S K I P^{\odot}$ studies have been undertaken and these can be broken down into two big categories, 1) $S K I P^{\odot}$ led by experts (such as motor development experts and physical education teachers), and 2) $S K I P^{\odot}$ led by teachers (typically early childhood teachers). The initial work with $S K I P^{\odot}$ consisted of direct instructional approaches where the expert teacher directed the child activities [27,28]. This work reported significant improvements in the FMS of children as a result of the $S K I P^{\odot}$ intervention, and compared to a business as usual control group. Later, we compared instructional approaches contrasting direct instruction (low child autonomy) to mastery motivational approaches (high child autonomy. This study found that both instructional approaches resulted in significant improvements in FMS compared to a business as usual control [31]. Other work has engaged parents as instructors [30] and added child-parent activities at home alongside the $S K I P^{\odot}$ program [41]. Most recently, we have implemented a $S K I P^{\odot}$ intervention that embedded motor skill activities with reading literacy activities [42] finding positive outcomes in both motor skills and emergent literacy skills like alphabet awareness and phonological awareness.

All of the work above used motor development experts as interveners. Although the results were positive, we were concerned about the translational power of these studies. Thus, our more recent work has focused on training early childhood classroom teachers to deliver $S K I P^{\odot}$. These studies have shown that it is possible to train early childhood teachers to deliver $S K I P^{\odot}$ effectively resulting in significant improvements in children's FMS competence [26,43]. Furthermore, we have begun to implement $S K I P^{\odot}$ in different countries (Indonesia, Wales, Turkey) and by doing so have a greater understanding of how to culturally tailor $S K I P^{\odot}$ to local conditions. The Cohens'd effect sizes for $S K I P^{\odot}$ range from 0.91 to 3.96 and can be found in Table 1. As might be expected, the effect sizes for experts are greater than those for teachers, but teachers can still bring about meaningful and significant changes in their children's FMS as a result of $S K I P^{\odot}$. It is important to note that in all of the $S K I P^{\odot}$ studies there were no significant improvements in the FMS of the control groups wo received the typical preschool curriculum (business as usual).

We have begun a systematic line of inquiry relative to implementing $S K I P^{\odot}$ in Indonesia resulting in a program called INDO-SKIP ${ }^{\odot}$. An initial study determined the feasibility and the effectiveness of an eight-week INDO$S K I P^{\odot}$ motor skill program on Indonesian preschool children's FMS competence [26]. Indonesian early childhood teachers were trained for nine-hours on motor skill development and $I N D O-S K I P^{\odot}$ lessons prior to delivering the $I N D O-S K I P^{\odot}$ program. This initial training was shown to be effective in improving teacher's knowledge of motor skills and teaching motor skills in a physical education setting. Teachers successfully acquired the prerequisite knowledge to teach the $I N D O-S K I P^{\odot}$ program. Prior to delivering INDO$S K I P^{\odot}$, preschoolers were delayed on their object control skills. After receiving 480 minutes of INDO-SKIP ${ }^{\odot}$ over eight weeks, twice a week, preschoolers significantly improved their object control skills and were no longer developmentally delayed in FMS. There was a large effect size (Cohens'd= 2.21). It was concluded that the INDO$S K I P^{\odot}$ program is feasible to be implemented in Indonesia and effective to improve children's object control skills. Further studies are needed to implement INDO-SKIP ${ }^{\odot}$ in diverse educational setting with larger samples.

Overall the $S K I P^{\odot}$ studies demonstrate the effectiveness of $S K I P^{\odot}$ for a variety of different children implemented by both experts and early childhood teachers. These studies also suggest that $S K I P^{\odot}$ can be flexibly tailored to different community settings across the world. It is clear that $S K I P^{\complement}$ can be successfully implemented within community settings either through early childhood child care (e.g. preschools) or through community-based sport settings.

\section{VIII.EVIDENCE-BASED IMPLICATIONS FOR EARLY PHYSICAL LITERACY PROGRAMS}

There are a number of recommendations based upon the $S K I P^{\odot}$ intervention literature:

1. Many young children, especially those from disadvantaged environments, demonstrate significant delays in FMS and are in need of motor skill intervention.

2. Both girls and boys are delayed in FMS, but girls are significantly lower in object control skills than boys. There are no differences between gender in locomotor skills. Thus, we need to make sure that FMS interventions 
particularly meet the needs of girls who are very delayed in their object control skills.

3. The control groups in the $S K I P^{\odot}$ studies showed no improvement in motor skills and were essentially "flat liners". Thus, what is typically delivered in our early childhood settings is not adequate to help the children develop the necessary levels of motor competence to be physically active and have high perceptions of motor competence. We need to enact policy in our early childhood settings ensuring that all children receive evidenced-based programming such as $S K I P^{\odot}$ to promote their motor competence.

4. Studies conducted by experts had larger effect sizes than SKIP ${ }^{\odot}$ studies delivered by teachers. However, teachers can be trained to deliver $S K I P^{\odot}$ effectively resulting in positive outcomes for children. This approach is a costeffective way to promote FMS development and physical activity in young children and has translational power.

5. The dose of motor skill interventions ranged from 360 mins to 7680 mins. Motor skill interventions with a minimum of 360 minutes of instructional time have shown significant improvement in children's motor competence, and up to large effect sizes [44]. The amount of time needed to be devoted to $S K I P^{\odot}$ is very minimal and feasible in early childhood settings.

In conclusion, early motor skill interventions such as $S K I P^{\odot}$ need to be delivered within our communities to promote the motor competence of young children, especially those from disadvantaged communities. These programs are essential to help our children get an active start and begin their lifespan journey towards physical literacy.

\section{REFERENCES}

[1] World Health Organization, "Obesity and overweight factsheet," 2018a, Available from: http://www.who.int/news-room/factsheets/detail/obesity-and-overweight

[2] World Health Organization, "Physical Activity," 2018b, Available from: http://www.who.int/news-room/fact-sheets/detail/physicalactivity

[3] S. E. Anderson, C. D. Economos, and A. Must, "Active play and screen time in US children aged 4 to 11 years in relation to sociodemographic and weight status characteristics: a nationally representative cross-sectional analysis," BMC Public health, 2008, 8(1), pp. 366-378.

[4] T. Hinkley, J. O. Salmon, A. D. Okely, D. Crawford, and K. Hesketh, "Preschoolers' physical activity, screen time, and compliance with recommendations," Medicine and science in sports and exercise, 2012, 44(3), pp. 458-465

[5] P. S. Tandon, C. Zhou, J. F. Sallis, K. L. Cain, L. D. Frank, and B. E. Saelens, "Home environment relationships with children's physical activity, sedentary time, and screen time by socioeconomic status," International Journal of Behavioral Nutrition and Physical Activity, 2012, 9(1), 88

[6] Central Intelligence Agency (CIA), "The world factbook. East \& South Asia: Indonesia," 2016, Available from: https://www.cia.gov/library/publications/the-worldfactbook/geos/id.html

[7] A. E. Collins, B. Pakiz, and C. L. Rock, "Factors associated with obesity in Indonesian adolescents," International Journal of Pediatric Obesity : Ijpo : an Official Journal of the International Association for the Study of Obesity, 2008, 3(1), pp. 58-64.

[8] Hendriyani, E. Hollander, L. d'Haenens, and J. W. Beentjes, "Children's media use in Indonesia," Asian Journal of Communication, 2012, 22(3), pp.304-319.

[9] M. Julia, M. M. Van Weissenbruch, H. A. Delemarre-van de Waal, and A. Surjono, "Influence of socioeconomic status on the prevalence of stunted growth and obesity in prepubertal Indonesian children," Food and Nutrition Bulletin, 2004, 25(4), pp. 354-360.

[10] C. N. Rachmi, M. Li, and B. L. Alison, "Overweight and obesity in Indonesia: prevalence and risk factors-a literature review," Public Health, 2017, 147, pp. 20-29.

[11] C. Roemling, and M. Qaim, "Obesity trends and determinants in Indonesia," Appetite, 2012, 58(3), pp.1005-13.

[12] World Health Organization (WHO), "Population-based approaches to childhood obesity prevention," 2012, Available from: http://apps.who.int/iris/bitstream/handle/10665/80149/97892.41504782 ?sequence $=1$

[13] A. A. Usfar, E. Lebenthal, Atmarita, E. Achadi, Soekirman, and H. Hadi, "Obesity as a poverty-related emerging nutrition problems: the case of Indonesia," Obesity Reviews: an Official Journal of the International Association for the Study of Obesity, 2010, 11(12), pp. 924-8.

[14] International Physical Literacy Association (IPLA), "The Definition of Physical Literacy," 2017, Available from: http://www.physicalliteracy.org.uk/.

[15] E. P. Roetert, and S. C. Jefferies, "Embracing physical literacy," Journal of Physical Education, Recreation and Dance, 2014, 85(8), pp. 38-40.

[16] Physical and Health Education (PHE) Canada, "Physical Literacy," 2018, Available from: https://phecanada.ca/activate/physical-literacy

[17] Australian Sports Commission (ASC), "Physical Literacy", 2018, Available https://www.ausport.gov.au/participating/physical_literacy

[18] D. Dudley, J. Cairney, N. Wainwright, D. Kriellaars, and D. Mitchell, "Critical considerations for physical literacy policy in public health, recreation, sport, and education agencies," Quest, 2017, 69(4), pp. 436452.

[19] D. F. Stodden, J. D. Goodway, S. J. Langendorger, M. A. Roberton, M. E. Rudisill, C. Garcia, and L. E. Garcia, "A developmental perspective on the role of motor skill competence in PA: an emergent relationship," National Association for Kinesiology and Physical Education in Higher Education, 2008, 60, pp. 290-306.

[20] D. Stodden, and J. D. Goodway, "The dynamic association between motor skill development and physical activity," Journal of Physical Education, Recreation \& Dance, 2007, 78(8), pp.33-49.

[21] L. E. Robinson, D. F. Stodden, L. M. Barnett, V. P. Lopes, S. W. Logan, L. P. Rodrigues, and E. D'Hondt, "Motor competence and its effect on positive developmental trajectories of health," Sports Medicine, 2015, 45(9), pp. 1273-1284.

[22] S. Harter, and R. Pike, "The pictorial scale of perceived competence and social acceptance for young children," Child Development, 1984, 55, pp.1969-1982.

[23] J. D. Goodway, and M. E. Rudisill, "Perceived physical competence and actual motor skill competence of African American preschool children," Adapted Physical Activity Quarterly, 1997, 14, pp. 314326.

[24] M. LeGear, L. Greyling, E. Sloan, R. I. Bell, P. Naylor, and V. A. Temple, "A window of opportunity? Motor skills and perceptions of competence of children in Kindergarten," International Journal of Behavioral Nutrition and Physical Activity, 2012, 9(1), pp. 1-5.

[25] L. M. Barnett, N. D. Ridgers, and J. Salmon, "Associations between young children's perceived and actual ball skill competence and physical activity," Journal of Science and Medicine in Sport, 2015, 18, 2, pp. 167-171.

[26] R., Famelia, "Getting An Active Start: Evaluating The Feasibility of INDO-SKIP to Promote Motor Competence, Perceived Motor Competence and Executive Function In Young, Muslim Children In Indonesia," OhioLINK Electronic Theses and Dissertations Center, Ohio State University, \& Ohio State University, 2018, unpublished.

[27] J. D. Goodway, and C. F. Branta, "Influence of a motor skill intervention on fundamental motor skill development of disadvantaged preschool children," Research Quarterly for Exercise and Sport, 2003, 74, 1, pp. 36-46.

[28] J. D. Goodway, H. Crowe, and P. Ward, "Effects of motor skill instruction on fundamental motor skill development" Adapted Physical Activity Quarterly, 2003, 20, pp. 298-314.

[29] J.D. Goodway, L. Robinson, and H. Crowe, "Gender differences in fundamental motor skill development in disadvantaged preschoolers in 
two geographical regions," Research Quarterly for Exercise \& Sport, 2010, 81(1), pp. 17-24.

[30] M. Hamilton, J. D. Goodway, and J. Haubenstricker, "Parent-assisted instruction in a motor skill program for at risk preschool children," Adapted Physical Activity Quarterly, 1999, 16, pp. 415-426.

[31] L. E. Robinson, and J. D. Goodway, "Instructional climates in preschool children who are at-risk. Part I: Object-control skill development," Research Quarterly for Exercise and Sport, 2009, 80, pp. 533-542.

[32] B. C. Spessato, C. Gabbard, N. Valentini, and M. Rudisill, "Gender differences in Brazilian children's fundamental movement skill performance," Early Child Development and Care, 2013, 183(7), pp. 916-923.

[33] S. A. Rosenberg, D. Zhang, \& C. C. Robinson, "Prevalence of developmental delays and participation in early intervention services for young children," Pediatrics, 2008, 121(6), pp. e1503-e1509.

[34] R. Famelia, E. Tsuda, S. Bakhiar., and J. D. Goodway, "Relationships among Perceived and Actual Motor Skill Competence and Physical Activity in Indonesian Preschoolers," Journal of Motor Learning and Development, in press.

[35] L. M. Barnett, E. van Beurden, P. J. Morgan, L. O. Brooks, and J. R. Beard, "Gender differences in motor skill proficiency from childhood to adolescence: A longitudinal study," Research quarterly for exercise and sport, 2010, 81(2), pp. 162-170.

[36] K. M. Newell, "Physical constraints to development of motor skills," in J. Thomas (Ed.), Motor Development During Preschool and Elementary Years, Minneapolis: Burgess, 1984, pp. 105-120.

[37] K. M. Newell, "Constraints on the development of coordination," in M. G. Wade \& H. T. A. Whiting (Eds.), Motor development in children: Aspects of coordination and control, Dordrecht, The Netherlands: Nijhoff, 1986, pp. 341-360.

[38] M.W. Metzler, Instructional models for physical education, 2nd ed., Scottsdale, AZ: Holcomb Hathaway, 2005.

[39] D. L. Gallahue, J. C. Ozmun, and J. D. Goodway, Understanding motor development: Infants, children, adolescents, adults, 7th ed, New York, NY: McGraw Hill, 2012.

[40] J. E. Clark, and J. S. Metcalfe, "The mountain of motor development: A metaphor," in. J. E. Clark \& J. H. Humphrey (Eds.), Motor Development: Research and Review: Vol. 2, Reston, VA: NASPE Publications, 2002, pp. 62-95.

[41] I. H. Altunsöz, and J. D. Goodway, "Skiping to motor competence: the influence of project successful kinesthetic instruction for preschoolers on motor competence of disadvantaged preschoolers," Physical Education and Sport Pedagogy, 2016, 21(4), pp. 366-385.

[42] Biancone, T. L, "The effects of an integrated early literacy and motor skill intervention on children's alphabet knowledge, initial sound awareness, and fundamental motor skill outcomes: an early efficacy study," OhioLINK Electronic Theses and Dissertations Center, Ohio State University, \& Ohio State University, 2018, unpublished.

[43] Brian, A. S. "Coaching teachers to SKIP: A feasibility trial to examine the influence of the T-SKIP package on the object control skills of Head Start preschoolers," OhioLINK Electronic Theses and Dissertations Center, Ohio State University, \& Ohio State University, 2014, unpublished.

[44] A. Brian, J. D. Goodway, J. A. Logan, and S. Sutherland, "SKIPing With Head Start Teachers: Influence of T-SKIP on Object-Control Skills," Research Quarterly for Exercise and Sport, 2017a, 88(4), pp. 479-491.

[45] A. Brian, J. D. Goodway, J. A. Logan, and S. Sutherland, "SKIPing with teachers: an early years motor skill intervention," Physical Education and Sport Pedagogy, 2017b, pp.1-13. 